\title{
Editorial
}

\section{Moving forward without leaving the ethical standard of publication}

\author{
Agus Rizal Ardy Hariandy Hamid, Felix Firyanto Widjaja
}

The first step for a researcher to find the data for a study and a clinician to answer the clinical question and improve the clinical services is looking for previous studies in a research database. Most of them will initially search in the established and well-known online databases i.e. MEDLINE (PubMed), Web of Science, Scopus, Embase, DOAJ, Proquest, EBSCO, etc. Thus, being indexed in these databases will lead a journal for being more accessible by the readers which are known to be the main purpose of a journal. ${ }^{1}$ More readers mean more citations which also mean more impact in scientific world. Furthermore, abstracting and indexing are also considered to be a reflection of a journal quality. By more new journals are published, the indexing system will help readers in choosing which journals worth to be read. The indexed journal is associated with a higher scientific quality. ${ }^{2}$ Then, in turn, it will improve the reputation of the journal as a reliable source of high-quality. ${ }^{1}$

Nowadays, Medical Journal of Indonesia (MJI) has been indexed in many databases, e.g.: Scopus, Embase, DOAJ, Proquest, EBSCO, and other indexing systems. After four years of being indexed in Scopus, Medical Journal of Indonesia has overcome some difficulties and had sufficient articles to be published and received more articles from various countries. Meanwhile, MJI still has a low citation and been classified into Q4 by SCImago Journal Ranks. ${ }^{3}$ Hence, accepted articles also need to be more selective in order to have more citations.

To be more visible for wider audience, a journal need to be indexed in more databases. Being indexed in more scientific database will also lead to the greater opportunity to build more solid reputation. ${ }^{1}$ In biomedical and health science, MEDLINE is the leading database which initially looked at by the researchers and clinicians. Web of Science is another database which is also popular. Thus, the editorial board continues to expand the possibility of $\mathrm{MJ}$ to be indexed in these databases. MJI has designed a strategic plan to improve the quality of publication for achieving the standard requirement of these databases. MJI has increased the selection of article to upgrade the quality of article and published more collaborative researches and articles.

Some improvements are and will be done in this year. Started this year, Universitas Indonesia as a publisher has been a member of Committee on Publication Ethics (COPE) and it is our liability to put highest standard on publication ethics. Faculty of Medicine Universitas Indonesia as the publisher of MJI is also included in COPE. Hence, all ethical disputes will take care by following COPE's guidelines, flowcharts, and cases examples. The authors, the reviewers, the editors, and the publisher have their own obligation for keeping the ethical standard of publication. The instruction for author has also been updated conforming to the recommendations for the conduct, reporting, editing, and publication of scholarly work in medical journals updated in December 2018.4 It is a journal's duty to inform all authors to have a highest standard in publishing their manuscript. Next, International Committee of Medical Journal Editors (ICMJE) has made a requirement for clinical trial to be registered in publicly accessible registration since 2005. ${ }^{5}$ Thus starting this year, MJI actively encourages and does an advocacy to all authors that are willing to submit clinical trial to do the registration.

To serve the authors better, we try to limit one week as a standard for each article being decided to be peer-reviewed. Meanwhile, we also make strict requirements in the initial administration assessment. The authors need to complete conflict of interest form, final checklist form, and ethical clearance for all type of research in two weeks. As a peer-review journal, $M J I$ has reformed the editorial and administration staff to improve and implement an efficient peer review

Copyright @ 2019 Authors. This is an open access article distributed under the terms of the Creative Commons Attribution-NonCommercial 4.0 International License (http:// creativecommons.org/licenses/by-nc/4.0/), which permits unrestricted non-commercial use, distribution, and reproduction in any medium, provided the original author and source are properly cited. 
process. Our editorial office still tries to shorten the duration of review. However, this process is still a difficult task since reviewing is a voluntary process and we respect all reviewer's time to do this process.

Furthermore, to serve readers better, MJI will have a new improvement look on the website and the printed version. The format for HTML and EPUB will also be generated in the mid-term of 2019. The system will be upgraded to Open Journal System version 3. Medical Journal of Indonesia will always improve its quality in order to serve the authors, readers, and reviewers better. Hopefully, these improvements will be a part of "Giant Leap" for MJI being more recognized by international readers and increases an impact factor to scientific world.

From Medical Journal of Indonesia pISSN: 0853-1773 • elSSN: 2252-8083

https://doi.org/10.13181/mji.v28i1.3733

Med J Indones. 2019;28:1-2
Corresponding author:

Agus Rizal Ardy Hariandy Hamid

E-mail: rizalhamid.urology@gmail.com

\section{REFERENCES}

1. Rajagopalan J. Journal indexing 101: Understanding the basics [Internet]. [updated 2015 May 20, 2015; cited 2019 April 24 ]. Available from: https://www.editage.com/insights/journalindexing-101-understanding-the-basics

2. Balhara YP. Indexed journal: what does it mean?. Lung India. 2012;29(2):193.

3. SCImago, (n.d.). SJR - SCImago Journal \& Country Rank [Internet]. Madrid: Scimago Lab; c2007-18 [cited 2019 April 22]. Available from: http://www.scimagojr.com.

4. International Committee of Medical Journal Editors. Recommendations for the Conduct, Reporting, Editing, and Publication of Scholarly Work in Medical Journals [Internet] [place unknown]: International Committee of Medical Journal Editors; c2019 [cited 2019 April 22]. Available from: http://www. icmje.org/.

5. Graf C, Wager E, Bowman A, Fiack S, Scott-Lichter D, Robinson A. Best practice guidelines on publication ethics: a publisher's perspective. Int J Clin Pract Suppl. 2007;61:1-26. 